\title{
O FETICHE DO CAPITAL INTELECTUAL: A IDEOLOGIA DO CONHECIMENTO E DA ADAPTAÇÃO NO CONTEXTO DA REESTRUTURAÇÃO PRODUTIVA DO CAPITAL
}

\author{
Giovanni Alves ${ }^{1}$ \\ Roberto Leme Batista ${ }^{2}$
}

O trabalhador cria tudo, e tudo de forma tal que enche de vergonha toda a Crítica, também em suas criações espirituais; os trabalhadores franceses e ingleses dão testemunho disso. O trabalhador cria até mesmo o ser humano; o Crítico permanecerá sempre um ser inumano, para o que lhe resta, por certo, a satisfação de ser um Crítico crítico.

ENGELS, F. in MARX, K. e ENGELS, F. A sagrada família. São Paulo: Boitempo, 2003, p. 30.

\begin{abstract}
RESUMO:
Neste artigo apresentamos uma discussão acerca do fetichismo do capital intelectual, ao analisar a ideologia do conhecimento e a exigência de adaptação do trabalhador no contexto da reestruturação do capital nas últimas décadas. Para tanto, analisamos a emergência dessa ideologia - através dos conceitos de sociedade do conhecimento, sociedade da informação, capital intelectual, entre outros - em alguns autores da área de gestão de recursos humanos, na sequência apresenta a crítica desse ideário a partir da análise de alguns autores do pensamento social crítico. Finalmente nos posicionamos no sentido de afirmar que se trata de uma nova versão do fetichismo na era da mundialização do capital.

Palavras-chave: Reestruturação produtiva. Ideologia. Capital Intelectual. Sociedade do conhecimento.

\section{THE FETISH OF INTELLECTUAL CAPITAL: THE IDEOLOGY OF KNOWLEDGE AND ADAPTATION IN THE CONTEXT OF RESTRUCTURING PROCESS OF CAPITAL}

\begin{abstract}
:
This article presents a discussion about the fetishism of the intellectual capital, analysing the ideology of knowledge and the need of adaptation of the worker in connection with the restructuring of capital in recent decades. We analyze the emergence of this ideology through the concepts of knowledge society, information society, intellectual capital, among others - in some authors of the area human resource management, following it presents the critique of this notion based on the analysis of some authors of critical social thought. Finally we position ourselves in order to assert that this is a new version of fetishism in the time of globalization of the capital.

Keywords: Restructuring. Ideology. Intellectual capital. Knowledge society.

O complexo de reestruturação produtiva que o capital desencadeou como ofensiva à crise de valorização, a partir da década de 1970, gerou um intenso debate sobre a formação dos trabalhadores para atender as exigências do mercado. A literatura sobre a formação profissional é prisioneira das análises sobre as expectativas individuais e identitárias diante da nova forma de sociabilidade do mundo do trabalho. A maioria das análises sobre este processo trilha uma perspectiva impressionista e limita-se a fazer apologia. Nesse sentido, afirmam que ocorrem ganhos para os trabalhadores, já que esses são convocados à participação e envolvimento, através dos CCQs e do trabalho polivalente e multifuncional.
\end{abstract}


Dissemina-se, dessa forma, uma ideologia focada nos "modelos" de formação profissional, ditos capazes de proporcionar aos indivíduos os assim chamados "novos atributos, habilidades e competências" como passaporte para o desenvolvimento da cidadania, através da garantia da empregabilidade, mesmo em condições adversas.

Essa concepção enfatiza o "aprender a aprender", "aprender a pensar", "aprender a ser" e "aprender a viver juntos", numa epistemologia voltada para a construção de condutas, ditas capazes de moldar e adaptar o indivíduo aos limites colocados pelo processo de permanentes mudanças no trabalho em decorrência das inovações tecnológicas e do desenvolvimento do trabalho flexível.

Efetivamente, trata-se da tentativa de consolidar um novo nexo psicofísico, através da "captura" da subjetividade do trabalhador. A ofensiva do capital, através da sua reestruturação produtiva, ou seja, o desenvolvimento de novas formas de organização e gestão da produção de cariz toyotista, das inovações tecnológicas, da flexibilização e desregulamentação, cria novas exigências para a formação do trabalho, seja ele simples ou complexo. Ou seja, as mudanças são qualitativas, sobretudo, no que tange às novas tecnologias de informação e comunicação. Portanto, presenciamos uma "grande revolução geral da tecnologia, engendrada pelo modo de produção capitalista, a revolução das redes informacionais". De tal forma que, instaura-se um processo de disseminação do "ciberespaço, seja como rede interativa, seja como rede controlativa, através das instâncias de produção e reprodução social. Além disso, com ela surge uma nova forma de ser da mercadoria: a mercadoria-informação" (ALVES, 2009, p. 57).

Assim, a mercadoria-informação constitui-se na última fronteira da modernização tardia. Surge com o fenômeno que Lukács cunhou como "capitalismo manipulatório". Nesse caso, "o modo de ser manipulatório é constituído por redes de informações lingüísticoimagéticas que atingem a subjetividade complexa de homens e mulheres." O processo é tão intenso que estas redes "impregnam o próprio fluxo societal, buscando constituir consentimentos e comportamentos pró-ativos e instaurar novas formas fetichizadas de intercâmbio societal." Nesse sentido, salientamos que estamos diante da quarta revolução tecnológica, cuja base técnica "propicia as condições materiais para o desenvolvimento pleno (e tensionado) do capitalismo global" (ALVES, 2009, p. 59).

Estas transformações engendradas pela ofensiva do capital geram uma sucessão de ideias e teorias acerca da nova realidade social, sobretudo, do mundo do trabalho. Disseminam-se novos conceitos e noções tais como sociedade do conhecimento, sociedade tecnológica, sociedade da informação, sociedade cognitiva, capital intelectual, empregabilidade, laboralidade, competência, aprender a aprender etc.

Esse texto constitui-se numa problematização sobre como esses conceitos aparecem na literatura, sobretudo, na área de gestão de recursos humanos e, a partir daí disseminam-se para a sociologia do trabalho e também para a educação.

É nesse sentido que se apresenta, por exemplo, o conceito de capital intelectual, como "a soma do conhecimento de todos em uma empresa." Salienta-se que a vantagem competitiva das empresas, na era global, é garantida por seu capital intelectual, uma vez que, "ao contrário dos ativos, com os quais empresários e contadores estão familiarizados propriedade, fábricas, equipamento, dinheiro -, o capital intelectual é intangível" (STEWART, 1998, p. XIII).

Desse ponto de vista, afirma-se que o capital intelectual "é o conhecimento da força de trabalho: o treinamento e a intuição de uma equipe de químicos que descobre uma nova droga de bilhões de dólares ou o know-how de trabalhadores que apresentam milhares de formas diferentes para melhorar a eficácia de uma indústria." De tal sorte, que pertence ao capital intelectual da empresa, também, "a rede eletrônica que transporta informação na empresa à velocidade da luz, permitindo-lhe reagir ao mercado mais rápido que suas rivais." Assim

Revista HISTEDBR On-line, Campinas, número especial, p. 154-174,ago.2010 - ISSN: 1676-2584 155 
como, o capital intelectual é também o processo de "cooperação - o aprendizado compartilhado - entre uma empresa e seus clientes que forja uma ligação entre eles, trazendo, com muita frequência, o cliente de volta" (STEWART, 1998, p. XIII).

Outrossim, esse autor busca sem maiores rodeios, definir "em uma frase: [que] $o$ capital intelectual constitui a matéria intelectual - conhecimento, informação, propriedade intelectual, experiência - que pode ser utilizada para gerar riqueza." Destaca-se ainda que o capital intelectual constitui "a capacidade mental coletiva. É difícil identificá-lo e mais difícil ainda distribuí-lo de forma eficaz. Porém, uma vez que o descobrimos e o exploramos, somos vitoriosos" (STEWART, 1998, p. XIII).

Esta concepção de conhecimento e de capital intelectual parte do pressuposto de que estamos vivendo uma nova era, ou seja, a da informação, que superou a forma econômica da era industrial. $\mathrm{O}$ mundo - segundo tal crença - está deixando para trás, a base econômica, "cujas principais fontes de riqueza eram físicas", uma época que as coisas "que comprávamos e vendíamos eram, realmente, coisas; podíamos tocá-las, cheirá-las, chutar seus pneus, bater suas portas ou ouvir um som agradável." Nesta época, afirma o autor, "a terra, recursos naturais como petróleo, minério e energia, e o trabalho humano e mecânico eram os ingredientes a partir dos quais se gerava riqueza." De tal forma que, naquela época, as organizações de negócios "eram planejadas para atrair capital - capital financeiro - a fim de desenvolver e gerenciar essas fontes de riqueza, e elas o faziam muito bem" (STEWART, 1998, p. XIV).

Nesta perspectiva, como se efetivamente vivêssemos em um mundo em que as coisas físicas tornaram-se secundárias, em decorrência da magnitude do conhecimento e da informação, Stewart (1998, p. XIV) afirma que:

Nesta nova era, a riqueza é produto do conhecimento. O conhecimento e a informação - não apenas o conhecimento científico, mas a notícia, a opinião, a diversão, a comunicação e o serviço - tornaram-se as matérias-primas básicas e os produtos mais importantes da economia. Compramos e vendemos conhecimento. Não se pode cheirá-lo ou tocá-lo; até o barulho da porta de um carro ao ser fechada provavelmente é o resultado de uma inteligente engenharia acústica. Hoje, os ativos capitais necessários à criação da riqueza não são a terra nem o trabalho físico, tampouco ferramentas mecânicas e fábricas: ao contrário, são os ativos baseados no conhecimento.

Em uma outra obra, Stewart (2002) utiliza os diferentes tipos e formas de chaves objeto físico, magnéticas - para demonstrar a importância dos códigos como componentes de informação para o processo de aberturas das portas. $\mathrm{O}$ autor demonstra o processo de evolução das chaves que vão dos objetos de metais ao cartão de plástico com tarja magnética em um dos lados. De tal forma que antigamente as chaves eram mais pesadas e menos complexas.

Entretanto, nesse caso, as chaves servem como "uma metáfora para ajudar a descrever como a chamada nova economia difere da antiga. Fundamentalmente, a economia do século XXI caracteriza-se pela intensidade de informação cada vez maior." De tal forma que, salienta o autor, "como as chaves, a economia envolve volumes crescentes de conhecimento - dados, interpretações, idéias. À semelhança do que ocorre com chaves, o valor está na informação em si - o valor situa-se no código da tarja magnética, não no plástico", acrescentando que, "esse conhecimento valioso independe de sua base física no momento: chave, site na Web, Palm Pilot" (STEWART, 2002, p. 29).

Nessa perspectiva o autor ressalta que "a era da informação não é apenas um slogan, mas um fato", destacando que "a economia baseada no conhecimento é, realmente, uma nova 
economia, com novas regras, exigindo novas maneiras de fazer negócios." Portanto, o autor é taxativo quanto à existência de uma nova economia, razão que o leva a afirmar que os argumentos que sustentam a sua existência, já foram expostos e comprovados exaustivamente "de modo a não deixar qualquer dúvida, a não ser entre uns poucos que não se dobram ante o irrefutável” (STEWART, 2002, p. 29-30).

Assim, Stewart (2002, p. 30, grifo nosso), define os três pilares em que se ancora a assim chamada economia do conhecimento, afirmando que:

O primeiro é: o conhecimento impregna tudo que compramos, vendemos e produzimos. Tornou-se o mais importante fator de produção. O segundo é um adjunto, um corolário do primeiro: os ativos do conhecimento - isto é, o capital intelectual - passaram a ser mais importantes para as empresas do que os ativos financeiros e físicos. O terceiro é: para prosperar na nova economia e explorar esses novos ativos cruciais, precisamos de um novo léxico, novas técnicas de gestão, novas tecnologias e novas estratégias. Sobre esses três pilares, erguem-se todas as leis da nova economia e os lucros por ela gerados.

Portanto, a premissa é que o conhecimento e a informação estão cada vez mais presentes em nossas vidas, pois aparecem embutidos em todos os produtos que usamos no cotidiano. Esse posicionamento reduz o conhecimento à forma útil, bem na perspectiva do capital, pois, "conhecimento não é soma, é agregação, interação, acumulação." O autor faz uma longa exposição sobre dados e informações - considerando a sociedade da informação e salienta que são menos do que conhecimento e do que sabedoria, pois, os dados e as informações "conectam-se entre si para formar conhecimento: são como peças de um mosaico, mas não é o desenho final. Bits de dados e informações - fatos, factóides - podem ser surpreendentes, sugestivos ou importantes, mas não são como conhecimentos em si" (STEWART, 2002, p. 31).

Nesse sentido, acrescenta que para alcançar o conhecimento, no sentido de expertise, é preciso tempo, pois, "o conhecimento dura mais do que a informação - e por vezes é eterno. Ter conhecimento, dominar um assunto, é algo diferente e maior do que saber de um fato ou possuir muitas informações a respeito de alguma coisa." Entretanto, o autor adota um posicionamento relativista e se contradiz ao afirmar que "é impossível estabelecer distinção nítida entre informação e conhecimento no caso de grupos muito grandes, pois o que é dado para alguém pode ser conhecimento para outrem, e vice-versa, dependendo do contexto" (STEWART, 2002, p. 31).

Stewart salienta que o capital físico e financeiro - os ativos convencionais - não desapareceram, porém, perderam importância, enquanto que, inevitavelmente o conhecimento se transforma no ativo mais importante para as organizações. É nesta perspectiva que o autor apresenta o conceito de capital intelectual, afirmando que "em termos simples, os ativos do conhecimento são talentos, habilidades, know-how, know-what e relacionamentos - assim como as máquinas e redes que os incorporam - utilizados para criar riqueza", acrescentando que em sua análise adota uma perspectiva diferente da contabilidade, pois, considera que "ativo é tudo aquilo que transforma matéria-prima em algo mais valioso" (STEWART, 2002, p. 38).

Desta forma, Stewart (2002, p. 40) afirma que:

Capital intelectual é o conhecimento que transforma as matérias-primas e as torna mais valiosas. As matérias-primas podem ser físicas - o conhecimento da fórmula da Coca-Cola é o ativo intelectual que converte uns poucos cents de açúcar, água, dióxido de carvão e flavorizantes artificiais em algo pelo 
qual se paga um dólar ou mais. Por vezes, as matérias-primas também são intangíveis, como a informação; um advogado, por exemplo, analisa os fatos do caso (matéria-prima), interpreta-os com base em seus conhecimentos da legislação pertinente (ativo intelectual) e produz um documento jurídico (output cujo valor é superior aos imputs, ou os fatos do caso em si). A idéia é simples, mas importante, pois, lembrando-se de que os ativos fixos transformam matérias-primas, tornando-as mais valiosas, começa-se a compreender o que é e como funciona o capital intelecutal.

Outrossim, salienta-se que "o capital intelectual de uma empresa é a soma de seu capital humano (talento), capital estrutural (propriedade intelectual, metodologias, software, documentos e outros artefatos de conhecimento), e capital em clientes (relacionamentos com os clientes)." Destaca-se que esses capitais são ativos tangíveis, e que "quem quiser saber por que uma empresa química obtém melhores resultados do que outra, a resposta estará em seu capital humano, estrutural e em clientes, não em suas caldeiras, tonéis, retortas e alambiques" (STEWART, 2002, p. 41).

Nonaka e Takeuchi (1997, p. 7) sustentam que o sucesso das empresas japonesas se encontra na capacidade de "criação do conhecimento organizacional." Esses autores entendem a criação do conhecimento organizacional como "a capacidade de uma empresa de criar novo conhecimento, difundi-lo na organização como um todo e incorporá-lo a produtos, serviços e sistemas." De forma muito estranha, para quem discute as empresas japonesas, esses autores não fazem uma única referência à Toyota ou a Taiichi Ohno, salientam que "a criação do conhecimento organizacional é a chave para as formas características com que as empresas japonesas inovam. Elas são peritas em fomentar a inovação de forma contínua, incremental e em espiral."

Esses autores salientam que as empresas japonesas possuem uma forma muito diferente de entendimento do conhecimento, quando comparadas às empresas ocidentais, pois entendem que quando expresso apenas em palavras o conhecimento é apenas a ponta do iceberg, por isso, "vêem o conhecimento como sendo basicamente 'tácito' - algo dificilmente visível e exprimível", uma vez que consideram que "o conhecimento tácito é altamente pessoal e difícil de formalizar, o que dificulta sua transmissão e compartilhamento com outros." Além do que, consideram que "o conhecimento tácito está profundamente enraizado nas ações e experiências de um indivíduo, bem como em suas emoções, valores e ideais" (NONAKA; TAKEUCHI, 1997, p. 7).

Ousaríamos afirmar que a questão do conhecimento nas empresas japonesas, não é outra coisa senão os princípios e nexos organizacionais - que primeiro se desenvolveram na Toyota e depois se disseminaram para as outras empresas japonesas, depois para empresas do Ocidente - que pressupõe o envolvimento e a participação estimulada e manipulada dos trabalhadores, ou seja, com o espírito do toyotismo, desenvolvido pelo Sistema Toyota de Produção, ocorre uma "captura" da subjetividade daqueles que sobrevivem da venda de sua força de trabalho. Nesse sentido, vejamos o que afirmam Nonaka e Takeuchi (1997, p. 11):

A explicação sobre a criação do novo conhecimento nas empresas japonesas resume-se à conversão do conhecimento tácito em conhecimento explícito. Ter um insight ou palpite altamente pessoal tem pouco valor para a empresa, a não ser que o indivíduo possa convertê-lo em conhecimento explícito, permitindo assim que ele seja partilhado com outros indivíduos na empresa. As empresas japonesas são particularmente boas em realizar essa troca entre conhecimento tácito e explícito durante a fase de desenvolvimento de produto. 
A ideologia da sociedade do conhecimento - disseminado por diversas organizações, principalmente pela UNESCO - visa produzir um consenso segundo o qual "todos os países do mundo, em ritmos diferentes, dependendo de seu nível de desenvolvimento, tornam-se inelutavelmente "sociedades do conhecimento", pois, no atual contexto "o saber e a informação dominam cada vez mais todos os setores da atividade humana", fazendo da aprendizagem "a chave do progresso" (PAPADOPOULOS, 2005, p. 25).

De tal forma, que para este autor o domínio do saber e da informação não se aplica somente à economia, pois, "que repousa essencialmente sobre o 'fator humano' no que se refere ao conhecimento, às qualificações, à capacidade de adaptação e ao espírito empreendedor." Parte-se da premissa que nesta sociedade o indivíduo necessita aprender durante toda a vida, por isso, a aprendizagem é um elemento essencial "seja para uma melhor adaptação à vida profissional seja por representar uma atividade autônoma. (...) mais do que nunca, devemos encontrar novos conceitos para novas políticas que permitam aprender em qualquer idade" (PAPADOPOULOS, 2005, p. 25).

Assim, afirma-se a necessidade da formação inicial "ter um caráter geral e abarcar tanto os aspectos cognitivos quanto os afetivos do desenvolvimento da criança." De tal forma que "devem lançar as bases de um saber sólido em todos os jovens e alimentar neles o gosto e a capacidade de adquirir novos conhecimentos - aprender a aprender -, sem o que não se consegue nenhum progresso" (PAPADOPOULOS, 2005, p. 25).

Com base nesse pressuposto, o autor propõe o desenvolvimento de um sistema amplo e flexível de ensino, que recorra ao setor público e privado, mas que possibilite "aos jovens prosseguir seus estudos ou ingressar na vida ativa, livrando-os assim da armadilha do desemprego." Para tanto, é necessário melhorar a qualidade do ensino técnico e também da formação profissional, como forma de "consolidar as bases de um saber adaptado às necessidades, considerando que o período das aprendizagens fundamentais prolonga-se cada vez mais e que a aquisição de competências relacionadas a um emprego muito específico fica para mais tarde" (PAPADOPOULOS, 2005, p. 26).

Assim, vai se apresentando o conceito de educação ao longo de toda a vida, numa perspectiva útil aos interesses das empresas, ou seja, do capital. Dessa maneira, salienta-se que "as políticas serão cada vez mais orientadas para os adultos ativos, cujas competências devem ser constantemente revistas em função das evoluções tecnológicas." Outrossim, destaca-se também que "deve-se dar uma atenção particular às mulheres que, em proporções cada vez maiores, desejam retornar à vida ativa, e à reciclagem dos trabalhadores vítimas da supressão de emprego." Revelador da rendição da educação à forma útil preconizada pelo mercado é a afirmação de que "será preciso empenhar-se mais em desenvolver a cooperação entre escola e empresa, em intensificar a formação garantida no local de trabalho, em melhorar a qualidade dos formadores e em adaptar os estágios e programas de formação às necessidades" (PAPADOPOULOS, 2005, p. 26).

Para Fonseca (1998, p. 8) a adaptabilidade, assim como a aprendizibilidade é o que "caracteriza a espécie humana", pois, sem elas, "a civilização não se poderia conceber, explicar e transformar". De tal forma que, a vida humana atualmente estaria marcada por megatendências cujos reflexos "não atravessam só a economia global e a mundialização da informação, mas elas estão projetando-se na educação e na qualificação dos recursos humanos do futuro." Nesta perspectiva, aponta para a existência de uma radicalidade desta forma de conceber o conhecimento, que constitui - segundo o autor -, um "novo modo de pensar e atuar", que juntamente com "a aceleração das mutações tecnológicas vão atingir todos os níveis da sociedade, e para isso é preciso prepararmo-nos educacionalmente de forma criativa, eficaz e dinâmica."

Nesta perspectiva de argumentação, o autor atribui a origem do conceito de educabilidade cognitiva ao psicólogo israelita Reuven Feuerstein que, "em termos de síntese, Revista HISTEDBR On-line, Campinas, número especial, p. 154-174, ago.2010 - ISSN: 1676-2584 
concebe a inteligência humana como um construto dinâmico flexível e modificável que está na base da adaptabilidade da espécie ao longo do seu percurso histórico-social" (FONSECA, 1998, p. 8).

Assim sendo, Fonseca (1998, p. 8) salienta que esta concepção é importante no atual contexto vivido pela espécie humana, afirmando que:

A revolução computacional, ora em movimento numa sociedade hoje definida como uma sociedade cognitiva, vai exigir cada vez mais conhecimento, criatividade e inovação, atributos cognitivos por excelência e de excelência, que não se podem adquirir apenas por percepção passiva e massificativa de informação, daí a urgência da educabilidade cognitiva.

Nesta cantilena, o educador português, salienta que a necessidade de diferentes sujeitos terem que se adaptar "às novas condições de produtividade e de qualidade", quer seja o "mais elementar estudante, quer o mais modesto trabalhador, depende inevitavelmente do potencial cognitivo e da educação cognitiva a que estiveram sujeitos." Assim, salienta-se que no caso do estudante, esta adaptação o "transformará num gerador ativo de informação e, consequentemente, num indivíduo mais autônomo e modificável e não num simples repetidor ou reprodutor de informação." Por outro lado, no caso do trabalhador, esta adaptação o fará tornar-se "mais talentoso e mais adaptado às mudanças que se vão operando inexoravelmente no seu emprego" (FONSECA, 1998, p. 9).

Este autor destaca a utilidade da educabilidade cognitiva, numa perspectiva de vislumbrar o futuro, assim como a quase totalidade da literatura sobre a sociedade do conhecimento, sociedade da informação e outros adjetivos usados para esta panacéia, afirmando que "a educabilidade cognitiva pode ter inúmeras aplicações, desde a educação até a formação, quer profissional, quer ao longo da vida, como hoje defendem muitas instituições internacionais." De tal maneira que efetivamente, o ato de "ensinar a aprender e aprender a ser inteligente não é um dom com que se nasce, mas sim o resultado de uma nova visão, melhor, de uma nova crença sobre o ser humano." Só nessa perspectiva de mudança, com esta nova crença "podemos alterar o futuro da sociedade, das famílias, das escolas e das empresas." Outrossim, uma vez que a educação se torna um problema de crença, salienta-se que "a educabilidade cognitiva, entendida na sua dimensão multicomponencial, multiexperiencial e multicontextual, materializa no fundo uma mensagem de otimismo e de prosperidade individual e coletiva" (FONSECA, 1998, p. 9).

Dessa forma, este autor compartilha da concepção de que a sociedade atual caracteriza-se por rápidas e complexas mutações - que, muito aceleradas - tornam "urgente preparar o ser humano para ser modificável e adaptável a situações novas e imprevisíveis", com destaque para o fato de que "o desenvolvimento social para a mudança subentende o desenvolvimento pessoal e, neste contexto, o enriquecimento cognitivo do indivíduo é uma das melhores formas de concretizá-lo" (FONSECA, 1998, p. 260).

Nesse sentido, após propor diversas estratégias pedagógicas especiais, com vistas a tornar possível a penetração nos subsistemas cognitivos do indivíduo, o educador português salienta que "só assim se podem atingir interações profundas que tendem a modificar estruturalmente a sua cognição." Manifesta, assim, veemente preocupação com a falta de qualquer perspectiva "metodológica diferencial de formação" voltada para atender as necessidades de muitos indivíduos, sobretudo, os trabalhadores, que não estão preparados para viverem na "nova cultura tecnológica que se instala progressivamente", o que coloca "em jogo novas modalidades de pensamento, de comunicação e de ação que o indivíduo deverá assimilar para responder aos novos desafios da produtividade" (FONSECA, 1998, p. 260). 
De acordo com esse autor a necessidade de adaptação às exigências da concorrência, da competitividade e da capacidade, da assim chamada nova economia, que se encontra em profunda, rápida e permanente inovação e mutação, que atinge não apenas o universo econômico, mas também o social "implica a mobilização máxima dos recursos humanos." De tal forma que "a polivalência, a flexibilidade e a adaptabilidade só podem concretizar-se quando se intervém na função cognitiva dos indivíduos." Salienta-se enfaticamente que o indivíduo não conseguirá "a assimilação e a criatividade da informação, [pois] torna-se passivo, arrogante, ameaçado e resistente à aprendizagem e à reaprendizagem", se não superar o baixo funcionamento cognitivo. Outrossim, lastima-se o fato da formação profissional desenvolvida de forma supletiva - não "contar com a intervenção nas funções cognitivas dos indivíduos" e, muito menos, levar "em conta a motivação, a relevância e a adequação aos seus interesses", assim como, "os interesses das empresas", levando os investimentos ao fracasso e a "custos sociais e econômicos incalculáveis". Assim, de forma trágica, "as perdas de potencial humano serão incomensuráveis e o reflexo no desenvolvimento social incontabilizável" (FONSECA, 1998, p. 267).

Destarte, as novas exigências do mercado levam o autor a clamar por uma reeducação cognitiva, ou melhor, uma reabilitação cognitiva da força de trabalho, pois - aprender a pensar -, se constitui numa "necessidade imperiosa." Assim, "para responder às mudanças cada vez freqüentes no mundo do trabalho, os indivíduos devem adquirir habilidades cognitivas básicas para se adaptarem e para melhorarem a sua condição" (FONSECA, 1998, p. 267).

Outrossim, o autor segue as trilhas de vários ideólogos da assim chamada mutação permanente da sociedade, no contexto da terceira onda, ou seja, da revolução computacional, salientando que as mudanças e as novas ondas do futuro "não só atingirão o campo dos negócios, como inevitavelmente o campo dos recursos humanos." Assim sendo, "em todos os campos, os paradigmas emergentes situarão o enfoque no conhecimento, na criatividade e na inovação, muito mais do que nos produtos" (FONSECA, 1998, p. 305).

Nessa perspectiva, tem-se que no futuro o poder será transformado no âmbito do trabalho e também da educação, impondo novos desafios a empresários, trabalhadores, professores e estudantes. O "verdadeiro choque do futuro" transformará a economia, abalando o seu caráter tradicional e centralizado, através de "uma inevitável transformação tecnológica, cada vez mais centrada na capacidade de aprender a aprender e de produzir inovação e criatividade." Dessa forma, afirma-se categoricamente que "a propriedade intelectual e a educabilidade cognitiva das organizações vão igualar, senão superar, no futuro, a produção de bens de consumo." Neste futuro, preconiza-se que os trabalhadores ou operários, assim como os estudantes e formandos - da era da informação -, "não serão passivos ou dependentes, nem submissos e silenciosos aos seus supervisores, muito menos dependentes de manuais de produção, (...) terão que ser talentosos e qualificados e cada vez mais responsáveis pelo seu posto de trabalho." De tal forma que à força de trabalho do futuro não bastará apenas "resolver novos problemas", pois, deverá "saber decidir sobre quais as soluções mais adequadas às situações de mudança que inevitavelmente surgirão" (FONSECA, 1998, p. 306).

Nessa perspectiva, cada trabalhador tem que assumir a responsabilidade direta pelo seu futuro "através de uma postura de iniciativa para implementar novas idéias e terão que se adaptar às novas condições de produtividade, estas cada vez mais marcadas pela qualidade, pela modernidade e pela competitividade." Isto porque as transformações em curso, decorrentes da "crise da sociedade industrial não resultará apenas da proliferação de desemprego em massa de operários ditos manuais, nem do aumento de falências." A estratégia para enfrentar essa tragédia histórica pressupõe que "a escala de mudança a pôr em marcha terá que jogar necessariamente com o enriquecimento cognitivo dos recursos humanos 
das empresas e das organizações para se adaptarem aos novos sistemas computacionais de informação e de produção" (FONSECA, 1998, p. 306).

Desse ponto de vista, o autor afirma que "o conjunto dinâmico dos empresários e dos trabalhadores", encontra-se mediante "a confusão, a frustração e o desespero, que caracterizam a força de trabalho". Ou seja, confrontam-se inevitavelmente "com os novos desafios da economia global”, o que leva Fonseca (1998, p. 306) a afirmar:

\begin{abstract}
Os novos desafios da competitividade, da modernidade e da qualidade da economia supersimbólica do século XXI, quer para os empresários e suas corporações, quer para os trabalhadores e suas organizações sindicais e, por simpatia funcional, para os estudantes e professores e respectivas escolas, bem como para os funcionários administrativos e seus governos, estão em assumir a mudança, em prevê-la e planificá-la. (...) A era da informação, e concomitantemente da aprendizagem acelerada e personalizada, vai transformar os recursos humanos do futuro, vai gerar um repensamento e uma reestruturação do trabalho e da sua formação, onde a melhoria da qualidade e da qualificação urgem, onde ela só pode atingir com novos programas de desenvolvimento do potencial cognitivo.
\end{abstract}

Não obstante, o autor salienta que o desenvolvimento do potencial cognitivo sofrerá obstáculos se "a miopia gerencial e arrogante e a resistência à mudança, que paira em grande parte no sistema produtivo, devem dar lugar à aprendizagem, ao conhecimento, ao pensar, ao refletir ao resolver novos desafios da atividade dinâmica que caracteriza a economia global." Outrossim, destaca que o contexto da "mundialização da economia só se identifica com uma gestão do imprevisível e da excelência, gestão esta contra a rotina, contra a mera redução de custos e contra a simples manutenção." A nova configuração histórica destrói a possibilidade de se pensar numa "perspectiva de trabalho seguro e estático, durante toda a vida." Razão pela qual, afirma-se que "os empresários e os trabalhadores devem cada vez mais investir no desenvolvimento do seu potencial de adaptabilidade e de empregabilidade." Para alcançar êxito, terão que buscar a "maximização das suas competências cognitivas" (FONSECA, 1998, p. 307).

Nesse sentido, salienta-se que "o investimento que se fizer no empresário e no trabalhador determinará o êxito da empresa e, por inerência, o êxito do emprego onde o trabalhador estiver inserido." Sempre numa perspectiva de desvendar o futuro, o autor destaca que ocorrerão mudanças de magnitudes imprevisíveis nos locais de emprego, de maneira "que, sem uma mudança estrutural na maneira de pensar, agir e comunicar, não vai ser possível a sobrevivência." De tal maneira que "aprender mais vai ser a condição-chave para ganhar mais, não necessariamente produzir mais, mas produzir melhor." Sendo assim, sacramenta que "as mudanças tão aceleradas que se avizinham são inexoráveis e inevitáveis" (FONSECA, 1998, p. 307).

Enfatiza-se que num mundo de mudanças aceleradas e permanentes os trabalhadores terão que adquirir "a capacidade de adaptação e de aprender a aprender e a reaprender", uma vez "que terão que ser reconvertidos em vez de despedidos, a flexibilidade e a modificabilidade para novos postos de trabalho vão surgir cada vez com mais veemência" (FONSECA, 1998, p. 307).

$\mathrm{Na}$ verdade, a ideologia da sociedade do conhecimento e seus codinomes sociedade da informação, sociedade tecnológica - ou outras variações terminológicas com que esse discurso se apresenta -, consiste em uma ressignificação da sociedade pós-industrial, conceito cunhado por Daniel Bell (1976). Os ideólogos adeptos dessa concepção se posicionam sobre a realidade social, de forma a não deixar margem de escape para alternativas, pois, o contexto da tal rápida e permanente mutação aparece na literatura - textos e documentos -, salientando 
a necessidade de estimular e cultivar a criatividade humana e que aos indivíduos não resta outra opção a não ser adaptar-se à nova realidade.

Esses posicionamentos apontam sempre para um futuro tecnológico inovador, para uma realidade social em prospectiva e permanente mutação. Faz-se apologia da assim chamada nova economia, porém não se problematiza as reais condições do sistema do capital no contexto da mundialização financeira. De tal sorte, que uma crítica desses posicionamentos demanda enfrentar os problemas reais que esta literatura - enquanto instrumentos do capitalismo manipulatório não podem fazer -, ou seja, cabe à crítica fazer uma contraofensiva ao sistema do capital monopolista e à mundialização financeira - o capitalismo especulativo e parasitário -, assim como, às novas formas de controle e dominação da era neoliberal. Portanto, é preciso desvelar a crise do capital e suas contradições estruturais que o capitalismo manipulatório persiste em esconder.

Para tanto, é necessário problematizar o mundo concreto, a realidade do exército de lázaros que vivem no desemprego, da precarização e superexploração da força de trabalho. É necessário apresentar o mundo do infortúnio, do analfabetismo, do desespero em que estão mergulhados milhões de seres sociais espalhados pelo globo terrestre. Ou seja, precisamos confrontar o mundo idílico e fantasioso da sociedade do conhecimento, onde as classes sociais - sobretudo o proletariado -, os conflitos e contradições desaparecem com o mundo real em que vivem os homens de carne e osso. A crítica a esta ideologia deve levar-nos a seguir as trilhas de Lojkine (2002, p. 232), que questiona:

[...] como interpretar a constituição, no mundo, de um imenso proletariado excluído da sociedade de consumo, sem um emprego estável, ameaçado pela fome, lançado nas favelas e agora já chegando mesmo aos bairros urbanizados (como é o caso do proletariado das grandes metrópoles americanas)? E, no Terceiro Mundo, não é esta classe - 'que suporta todos os ônus da sociedade, sem desfrutar de suas vantagens, que é expulsa da sociedade' (K. Marx, 1968, p. 68) - que constitui a maioria da sociedade? E não se localiza aí um outro mundo, muito mais próximo do proletariado inglês do século XIX (pelo menos nos países recentemente industrializados) do que dos 'proletários de colarinho branco' da nossa sociedade informacional? Ou, para dizer de outra maneira: a revolução informacional... não seria uma revolução para os países ricos e desenvolvidos?

Nos limites desse artigo, limitaremos nossa discussão ao âmbito da pedagogia do aprender a aprender que é o alicerce onde a sociedade do conhecimento busca sustenta-se. Nesse sentido, remetemos os interessados em aprofundar a leitura sobre a realidade da classe trabalhadora, a precarização e superexploração da força de trabalho aos seguintes autores ${ }^{3}$.

\section{A crítica à "sociedade do conhecimento" e à pedagogia do "aprender a aprender"}

Um dos autores que trava um debate aberto contra a perspectiva ideológica da sociedade do conhecimento, o ideário do "aprender a aprender" e toda a panacéia conceitual que se desenvolve em torno dessas ideias é Newton Duarte. Este autor salienta que seu objetivo é demonstrar as relações entre "as pedagogias do 'aprender a aprender' e algumas ilusões da assim chamada sociedade do conhecimento." Nesse sentido, afirma que "há um forte movimento internacional de revigoramento das concepções educacionais calcadas no lema 'aprender a aprender." $\mathrm{O}$ autor explicita ser correto o uso do termo revigoramento em vez de retomada, pois este deixaria "a desejar em termos de fidelidade à história (...) porque a rigor o 'aprender a aprender' nunca deixou de estar presente no ideário dos educadores, como 
um lema carregado de um julgamento de valor totalmente positivo (...)" (DUARTE, 2001, p. 29).

Nessa perspectiva, ressalta que o ideário pedagógico escolanovista do "aprender a aprender" sobreviveu às fortes críticas que a ele foram dirigidas por diversos autores nas últimas décadas, pois "manteve-se presente e forte no ideário pedagógico independentemente da existência ou não de menções explícitas ao movimento escolanovista e aos autores que foram as principais referências desse movimento" (DUARTE, 2001, p. 29).

Duarte destaca que um dos meios importantes para o revigoramento do "aprender a aprender", foi a intensa divulgação dos referenciais da epistemologia e da psicologia genéticas de Jean Piaget para a educação, por meio do "movimento construtivista que, no Brasil, tornou-se um grande modismo a partir da década de 1980, defendendo princípios muito próximos aos do movimento escolanovista." De tal sorte que o construtivismo não pode ser analisado como um fenômeno desvinculado da totalidade do contexto da mundialização do capital nas últimas décadas.

Nesse sentido, salienta que na América Latina esse movimento se fortaleceu com o processo de aguçamento da mundialização do capital e com a disseminação "do modelo econômico, político e ideológico neoliberal e também de seus correspondentes no plano teórico, o pós-modernismo e o pós-estruturalismo." De fato, foi nesse contexto em que o capitalismo promoveu uma intensa luta para perpetuar-se que "o lema 'aprender a aprender' é apresentado como a palavra de ordem que caracterizaria uma educação democrática" (DUARTE, 2001, p. 30).

Duarte (2001, p. 32) enfatiza que o construtivismo "retoma em outras roupagens muitas das idéias fundamentais da escola nova", exercendo papel decisivo para o processo de revigoramento do lema "aprender a aprender" nos ideários que conduzem as reforma educacionais contemporâneas.

Portanto, para Duarte, os ideários escolanovista e construtivista têm em comum os mesmos posicionamentos valorativos do lema "aprender a aprender". Nesse sentido, salienta que o primeiro posicionamento valorativo contido neste lema "seria o de que as aprendizagens que o indivíduo realiza por si mesmo, nas quais está a transmissão, por outros indivíduos, de conhecimentos e experiências, é tida como mais desejável." Este posicionamento parte da premissa que o indivíduo que aprende sozinho aumenta sua autonomia, enquanto aquele que aprende através da transmissão de outra pessoa não desenvolve sua autonomia, já que essa forma de aprendizagem constitui-se num obstáculo para tal processo (DUARTE, 2001, p. 34).

Duarte posiciona-se de forma a não discordar que a educação contribua para o desenvolvimento da capacidade e a iniciativa do indivíduo "buscar por si mesmo novos conhecimentos, a autonomia intelectual, a liberdade de pensamento e de expressão." Entretanto, posiciona-se acidamente contra o posicionamento valorativo que dispensa a importância do educador no processo de transmissão do conhecimento, por isso, explicita que sua 'discordância reside na valoração, contida no 'aprender a aprender', das aprendizagens que o indivíduo realiza sozinho como mais desejáveis do que aquelas que ele realiza por meio da transmissão de conhecimentos por outras pessoas" (DUARTE, 2001, p. 35).

O segundo posicionamento valorativo que contém o lema "aprender a aprender" é a "idéia de que é mais importante o aluno desenvolver um método de aquisição, elaboração, descoberta, construção de conhecimentos, do que aprender os conhecimentos que foram descobertos e elaborados por outras pessoas." Isto porque, de acordo com o lema "aprender a aprender" a aquisição do método científico é mais importante "do que o conhecimento científico já existente." Nessa perspectiva, o autor salienta que "esse segundo posicionamento valorativo não pode ser separado do primeiro, pois o indivíduo, nessa concepção, só poderia adquirir o método de investigação, só poderia 'aprender a aprender' por meio de uma atividade autônoma" (DUARTE, 2001, p. 35). 
Dessa forma, há no lema "aprender a aprender" uma supervalorização do método do conhecimento e o desprezo pelo conhecimento como produto, ou seja, esse lema apóia-se "nas dicotomias entre conteúdo e forma e entre processo e produto", sem contar que, "articula-se também à idéia de que uma educação democrática não pode privilegiar uma determinada concepção ideológica, política etc. Uma educação democrática [conforme os pressupostos construtivistas] seria uma educação relativista" (DUARTE, 2001, p. 37).

Portanto, o segundo posicionamento valorativo do lema "aprender a aprender" pressupõe a ênfase e primazia do método de construção do conhecimento em detrimento à apropriação do conhecimento já existente. Outro fator determinante nesse posicionamento é a questão da neutralidade em relação ao conteúdo da educação moral, assim como a posição relativista em questões política e ideológica.

O lema "aprender a aprender" contém como terceiro posicionamento valorativo o "princípio segundo o qual a atividade do aluno, para ser verdadeiramente educativa, deve ser impulsionada pelos interesses e necessidades da própria criança [educando]." O terceiro posicionamento valorativo diferentemente dos dois posicionamentos anteriores determina que o aluno, além de buscar por si mesmo o conhecimento, tem que construir sozinho o seu método de conhecer. Para tanto, "é preciso também que o motor desse processo seja uma necessidade inerente à própria atividade da criança, ou seja, é preciso que a educação esteja inserida de maneira funcional na atividade da criança, na linha da concepção de educação funcional de Claparède" (DUARTE, 2001, p. 40-41).

O quarto posicionamento valorativo contido no lema "aprender a aprender", detectado por Duarte, é o de maior relevância para efeito desse artigo, pois se relaciona à questão da necessidade do indivíduo buscar permanentemente o conhecimento para acompanhar o acelerado processo de mudança que ocorre na sociedade.

Nesse sentido, o autor salienta que o pressuposto desse posicionamento valorativo "é o de que a educação deve preparar os indivíduos para acompanharem a sociedade em acelerado processo de mudança," de tal forma que, contrariamente às sociedades estáticas, nas quais a educação tradicional transmitia os "conhecimentos e tradições produzidos pelas gerações passadas [que] era suficiente para assegurar a formação das novas gerações," na sociedade dinâmica e em permanente mutação em que vivemos é "a educação nova (ou construtivista)" que deve pautar a educação, considerando que "as transformações em ritmo acelerado tornam os conhecimentos cada vez mais provisórios, pois um conhecimento que hoje é tido como verdadeiro pode ser superado em poucos anos ou mesmo em alguns meses." O autor destaca que para esse posicionamento valorativo, para nós ideológico, "o indivíduo que não aprender a se atualizar estará condenado ao eterno anacronismo, à eterna defasagem de seus conhecimentos" (DUARTE, 2001, p. 41).

O autor enfatiza ainda que o "aprender a aprender" é apresentado por seus apologetas "como uma arma na competição por postos de trabalho, na luta contra o desemprego." Fundamentalmente, o lema do "aprender a aprender" apresenta-se "na sua forma mais crua, mostra assim seu verdadeiro núcleo fundamental: trata-se de um lema que sintetiza uma concepção educacional voltada para a formação da capacidade adaptativa dos indivíduos." Assim, Duarte (2001, p. 42) afirma que:

Quando educadores e psicólogos apresentam o 'aprender a aprender' como síntese de uma educação destinada a formar indivíduos criativos, é importante atentar para um detalhe fundamental: essa criatividade não deve ser confundida com busca de transformações radicais na realidade social, busca de superação radical na sociedade capitalista, mas sim criatividade em termos de capacidade de encontrar novas formas de ação que permitam 
melhor adaptação aos ditames do processo de produção e reprodução do capital.

Canário (2003) também apresenta interessantes subsídios sobre a ideologia da educação na virada do século. Esse autor salienta que há uma centralidade das políticas de educação e formação atualmente na Europa, como resultado da "articulação que é estabelecida entre a educação e a actividade económica (produtividade e emprego) e que conduz a que as políticas de educação e formação sejam uma 'tradução' das preocupações de gestão da mão-de-obra, ou seja, das políticas de emprego." É no quadro do debate entre educação e formação da mão-de-obra que a União Européia apresentou o "Memorando sobre a Aprendizagem ao Longo da Vida." O autor desenvolve uma reflexão visando contribuir para "esclarecer e compreender de que modo, e em que sentido, evoluíram as concepções sobre a educação e a formação na Europa, durante os últimos trinta anos."4

Numa perspectiva crítica com a evolução das ideologias educacionais nas últimas décadas, Canário (2003, p. 193) destaca que:

Finalmente, e em contradição total com a concepção da educação como um processo de 'aprender a ser', o alargamento da forma escolar a todos os tempos e espaços contribuiu para desvalorizar as aquisições humanas realizadas por via não escolar, a partir de vivências experienciais.

Destarte, com o crescimento da intervenção dos Organismos Multilaterais nas questões educativas, depois de algumas décadas ficou claro "de que modo o movimento da educação permanente contribuiu para que, no início deste novo milênio, a educação permaneça refém da forma escolar". De tal maneira, é lamentável, que durante os últimos trinta anos, tenhamos presenciado "em nome do desenvolvimento da educação (...) uma 'erosão' progressiva e continuada das referências iniciais da educação permanente que conduziu à sua perversão." Assim, é a partir desta "perversão que se afirmam e constroem, na actualidade, as políticas de 'aprendizagem ao longo da vida."” (CANÁRIO, 2003, 193).

Canário destaca a importância, na década de 1970, do movimento de educação permanente, salientando que "num contexto de iniciativa popular, este movimento permitiu ou incentivou" importantes experiências educativas, ainda que estas fossem embrionárias e minoritárias. Em Portugal, por exemplo, após o 25 de Abril, sucedeu-se importantes experiências de educação popular. Entretanto, destaca que atualmente usa-se a educação permanente para justificar ideologicamente a importância e a forma da educação.

A ruptura entre a concepção de "Educação Permanente" e a de "Aprendizagem ao Longo da Vida", é um processo que "inscreve-se e só é compreensível no quadro de um conjunto mais vasto de transformações de natureza social que afectaram a economia, o trabalho e a formação, no último quartel do século XX" (CANÁRIO, 2003, p. 196).

A década de 1990 foi o tempo da proliferação do lema "aprendizagem ao longo da vida", que vista de forma ingênua e apressada "pode ser entendido como o retomar voluntarista da 'aposta' na educação que marcou os anos 70." Entretanto, a ideologia em voga atualmente é completamente diferente do movimento da educação permanente, pois, "se nas décadas de 60 e 70 imperou a controvérsia, hoje impera o 'consenso', ou seja, a ausência de debate e a negação do pensamento crítico." Com fundamento nesse "consenso" a Comissão Européia, por meio do Livro Branco (Ensegner et Aprendre. Vers la société cognitive) decretou "que devem ser considerados como ultrapassados os debates sobre 'a concepção das missões dos sistemas educativos e de formação." De fato isto significa que "a partir de agora só se admite a discussão sobre os meios, negando-se qualquer pertinência à discussão dos 
fins, ou seja, àquilo que está no cerne da política e da cidadania, a determinação pelos humanos do seu devir individual ou colectivo" (CANÁRIO, 2003, p. 193).

Enquanto que os fundamentos e justificativas do movimento pela "educação permanente" eram de caráter eminentemente filosófico e político, a argumentação que justifica e fundamenta a ideologia da "aprendizagem ao longo da vida" possui "natureza inteiramente diversa e tem como base três grandes categorias de argumentos que remetem para a evolução tecnológica, para a eficácia produtiva e para a coesão social" (CANÁRIO, 2003, p. 193).

Foi nessa perspectiva que a Comissão das Comunidades Européias formulou o "Memorando sobre Aprendizagem ao Longo da Vida." O referido Memorando apresenta uma "primeira categoria de argumentos [que] diz respeito a uma rápida e profunda mutação de carácter tecnológico", que compara às transformações ocorridas durante a Revolução Industrial, pois a mutação tecnológica marca 'a transição para uma 'Era do Conhecimento', concomitante com uma 'Nova Economia' que tornaria obsoletas as competências actualmente existentes" (CANÁRIO, 2003, p. 194).

Assim, as transformações tecnológicas "aparecem como elementos de sobredeteminação da sociedade e da vida humana," de tal maneira que, conforme preconiza o Livro Branco "a tecnologia digital está a transformar todos os aspectos da vida dos cidadãos, enquanto que a biotecnologia poderá vir um dia alterar a própria vida." O lema "Aprendizagem ao Longo da Vida" contém uma dupla exigência, "por um lado, por parte dos empregadores "que exigem a capacidade de rapidamente aprender e adquirir novas competências, adaptando-se a novos desafios e situações"” (CANÁRIO, 2003, p. 194).

Em assim sendo, o mercado de trabalho passou a exigir novos perfis de competências, qualificações e também de experiências para atender as necessidades das mutações. Nesse sentido Canário destaca que a questão candente é que a "rápida evolução tecnológica, apresentada como algo de inelutável cuja origem permanece misteriosa, está na raiz de mutações sociais e econômicas relativamente às quais é imperativa uma adaptação". Dessa maneira, a "Aprendizagem ao Longo da Vida" constitui-se numa "estratégia que visa fornecer as condições para essa adaptação", vislumbra-se, assim, a perspectiva - manipulação ideológica - de todos participarem da construção do futuro (CANÁRIO, 2003, p. 194).

A segunda categoria de argumentos que reforçam os pressupostos que dão sustentação à ideologia da "Aprendizagem ao Longo da Vida", diz respeito à eficácia da atividade produtiva, que giram "em torno da trindade (santíssima?) da produtividade, competitividade e empregabilidade." Estes argumentos apelam para uma inovação na gestão da força de trabalho, visando torná-la apta a responder às mudanças decorrentes das transformações nas diferentes esferas do trabalho. O Memorando destaca que esse processo desequilibrou os mercados de trabalho, criando um elevado nível de desemprego estrutural (CANÁRIO, 2003, p. 194).

Nesse sentido, Canário (2003, p. 194) destaca que:

A Aprendizagem ao Longo da Vida é precisamente definida, no Memorando, como uma medida integrada na 'Estratégia Européia de Emprego' e 'visando melhorar conhecimentos, aptidões e competências [CCE 2000, p. 3]. A produção das 'novas competências' requeridas pela transição da Europa 'para uma sociedade e uma economia assentes no conhecimento' passa a instituir-se como 'a chave do reforço da competitividade da Europa e da melhoria da empregabilidade e da adaptabilidade da força de trabalho' [idem, p. 7]. É esta preocupação em melhorar a 'empregabilidade' e a 'adaptabilidade' da mão-de-obra que constituiu o factor de catalisação que, nos anos 90, viria a colocar na agenda política a questão da Aprendizagem ao Longo da Vida. 
A terceira categoria de argumentos que justificam o lema da "Aprendizagem ao Longo da Vida" reveste-se de uma magnitude vital ao metabolismo do capital. Nesse sentido, o autor salienta que esses argumentos organizam-se "em torno da temática da 'coesão social' (que é o reverso do 'combate à exclusão') e que traduz a preocupação central de combater ou prevenir formas de conflitualidade social que poderiam abalar o sucesso da nova ordem econômica." Portanto, a questão é a busca da conciliação do crescimento econômico, simultaneamente ao reforço da coesão social. Ou seja, "as preocupações com a 'coesão social' representam a tradução, no contexto da 'nova questão social', do espectro das 'classes perigosas' que preocupou, no século XIX, as classes dirigentes” (CANÁRIO, 2003, p. 194).

Portanto, as três categorias de argumentação do ideário da "Aprendizagem ao Longo da Vida", apesar de serem aparentemente diversas, "são vertentes distintas de uma mesma lógica argumentativa: a subordinação funcional das políticas de educação e de formação à racionalidade económica dominante, baseada na produção e acumulação de riqueza" (CANÁRIO, 2003, p. 195).

As ofensivas do capital intensificam-se num processo crescente de "monetarização" da vida, tornando obsoletas as "novas fronteiras do dinheiro" e também as antigas fronteiras nacionais. Porém, a principal o capital se dá contra o mundo do trabalho, levando ao rompimento do compromisso político do welfare state que articulava a democracia e o capitalismo, por meio do Estado-providência, conduzindo o sistema do capital, principalmente na Europa, a uma situação de desemprego incontrolável. De tal forma que "as transformações do mundo do trabalho, na Europa, traduzem-se, a partir dos anos 70, por um fenómeno de desemprego estrutural de massas que atinge, em primeiro lugar, os países mais 'modernos' e mais 'competitivos' (França, Alemanha e Inglaterra)." Efetivamente a denominada "crise do trabalho" corresponde de fato a uma crise do capital, que "com modalidades diferenciadas, a uma tendência global (...) [que] configura (...) uma crise civilizacional que é concomitante com um agravamento sistemático dos vários tipos de desigualdade social" (CANÁRIO, 2003, p. 196).

De tal forma que o mundo passou a conviver com níveis de desemprego que eram "absolutamente impensáveis nos anos 60, pela sua visibilidade social [que] tendem a 'esconder' aquela que é a mais decisiva e brutal das mudanças, ou seja, a que põe em causa a natureza do vínculo laboral, tornado precário." Nesse sentido, os teóricos e apologetas da assim chamada "nova economia", denominam esse processo como "flexibilização do emprego", que "corresponde a 'redesenhar o mercado de emprego' com base na crescente precarização dos vínculos de trabalho." Esta precarização encontra uma aceitação social, uma vez que é "preparada e facilitada pela ameaça constituída pelos elevados níveis de desemprego, o que permite elevar os níveis de tolerância à injustiça social e tende, assim, a banalizá-la." Assim, o custo social e individual decorrentes das transformações é elevado "e exprime-se quer pela intensificação dos processos e situações de 'sofrimento' associados ao trabalho", da mesma forma como conduzem à "corrosão do caráter", questões tão caras a autores como Dejours e Sennett (CANÁRIO, 2003, p. 196).

Estas transformações mudaram radicalmente a realidade do mundo do trabalho, pois aumentaram o desemprego e incrementaram um brutal processo de precarização do trabalho, provocou também mudanças fundamentais no quesito formação, provocando a ressignificação do conceito de qualificação, o que levou à predominância da noção de competência como requisito para a empregabilidade.

Ocorreu então o desmonte do estatuto profissional da era taylorista/fordista e o consequente destroçamento da formação, da qualificação e do salário que uma vez que eram até então estabelecidos por negociações, acordos e convenções coletivas e constituíam-se em “quadros de referências estáveis para a construção de identidades profissionais." Assim, o 
"novo espírito do capitalismo" com suas novas formas de gestão gerou uma crise das identidades profissionais que "é o resultado convergente do desemprego de massas, da precarização do trabalho." É nesse contexto que a qualificação profissional cedeu "lugar à competência, avaliada ao nível de cada indivíduo e por cada entidade empregadora", dessa forma cada indivíduo deve tornar-se responsável pela sua empregabilidade, uma vez que "os problemas do trabalho tendem a deixar de ser sociais para passarem a ser percepcionados como problemas individuais" (CANÁRIO, 2003, p. 197).

Portanto, o discurso ideológico que se configurou nos anos 90, pertinentes ao mundo do trabalho, é totalmente diferente daquele que imperou durante os anos 70, de tal maneira que a equação para os problemas nos anos 90 "corresponde a uma outra maneira de 'ler' o mundo que constitui o pano de fundo ideológico que subjaz à política da 'Aprendizagem ao Longo da Vida." Assim sendo, "a mudança de paradigma pode ser apresentada, de modo sintético, em função de três dimensões: uma dimensão econòmica, uma dimensão social, e uma dimensão educativa" (CANÁRIO, 2003, p. 197).

A dimensão econômica nos anos 60, garantia uma centralidade ao conceito de desenvolvimento, que equacionava a realidade ao classificar os países e regiões do globo em desenvolvidos, em vias de desenvolvimento e subdesenvolvidos, numa "visão simultaneamente voluntarista e optimista que via no 'progresso' o motor da evolução social, conducente à criação de 'sociedades da abundância'." Na fase dourada do capitalismo, depois da Segunda Guerra Mundial, disseminou-se a ideia segundo a qual haveria uma melhoria permanente das condições de vida, graças ao crescimento econômico que faria aumentar ano a ano os investimentos, a produção e os rendimentos. Nos anos 90, muda-se radicalmente o discurso ideológico sobre as relações econômicas, pois, "o referencial do 'desenvolvimento' deu lugar ao referencial da 'mundialização' encarada como um conjunto de desafios, que nos são exteriores, aos quais é preciso responder e, sobretudo, adaptar-se" (CANÁRIO, 2003, p. 197).

Nos anos 60 imperava o ideário de justiça social em diferentes vertentes do pensamento social. Este ideário estava posto tanto para a perspectiva cristã que tratava a questão social como problemas de pobreza, como para a perspectiva marxista que tratava como exploração. Entretanto, nos anos 90, o conceito da justiça social "perde a sua centralidade para dar lugar a preocupações de controlo social, organizadas a partir do conceito de coesão social." O processo de construção do consenso nesta perspectiva pressupõe “"promover a coesão social' ou 'lutar contra a exclusão social' [que] são duas maneiras diferentes de dizer a mesma coisa, ou seja, defender a preservação da 'paz', quer dizer, da 'ordem' social” (CANÁRIO, 2003, p. 198).

Segundo Canário, "um relatório da OCDE, publicado em 1997, consagrado à temática da 'coesão social' é particularmente esclarecedor quanto ao sentido desta preocupação", pois reconhece o acerto das medidas econômicas adotadas pelos países membros da OCDE, e salienta que as mesmas estão voltadas para "o ajustamento estrutural e a mundialização da produção e da distribuição." Ao mesmo tempo, apresenta uma preocupação com as consequências sociais de tais medidas, pois, "o desencadeamento político cada vez mais vivo, resultado de uma polarização crescente dos rendimentos, da persistência de níveis elevados de desemprego e de exclusão social cada vez mais presente." Não deixa de reconhecer a presença nos países membros de um "mal-estar social crescente [que] constitui uma séria 'ameaça para o movimento de flexibilização da economia e para as medidas que favorecem a concorrência, a mundialização e a inovação tecnológica"” (CANÁRIO, 2003, p. 198).

Nesse sentido, Canário salienta que "por outras palavras, as preocupações manifestadas com a coesão social justificam-se por esta constituir uma condição necessária para a consolidação de um projecto económico baseado na integração supranacional." O autor faz um arremate dessa questão, tomando por base as preocupações de Wacquant, Revista HISTEDBR On-line, Campinas, número especial, p. 154-174,ago.2010 - ISSN: 1676-2584 169 
sentenciando que "é neste quadro de preocupações com a 'ordem social' que é possível entender como se passou de uma 'guerra à pobreza', nos anos 60, para uma criminalização da pobreza, nos anos 90, a qual configura uma 'guerra aos pobres', traduzida pelo seu encarceramento sistemático." Ou seja, "o Estado social (promotor do 'bem-estar') nos anos 60 tende a ser substituído, nos anos 90, por um Estado penal” (CANÁRIO, 2003, p. 198).

A justificativa apresentada pelo discurso ideológico da "aprendizagem ao longo da vida", assim como a do conjunto das políticas sociais, parece fundamentar-se em fatos, à medida que procura "instituir-se como uma resposta neutra e, até, como a única possível e lógica." Canário lembra-nos que Bourdieu e Wacquant destacaram o fato dessa justificativa repousar sobre uma retórica que "constitui 'uma nova vulgata planetária', construída a partir de um vocabulário vindo não se sabe donde e que 'está em todas as bocas'." Portanto, o vocabulário que se desenvolve envolto à ideologia em questão se explicita no entorno de palavras-chave, tais como, entre outras: “'mundialização', 'flexibilidade', 'empregabilidade', 'exclusão social', coesão social', 'nova economia', etc." Por outro lado, esse vocabulário exclui categorias importantes 'como: 'capitalismo', 'classe', 'exploração', 'dominação', 'desigualdade', etc.” (CANÁRIO, 2003, p. 199).

Maria Célia Marcondes de Moraes, também traz uma importante contribuição crítica a esse tipo de ideologia, ao demonstrar que o problema do conhecimento no atual contexto histórico, não pode ser tratado de forma indiferente por quem se preocupa com a formação. Afinal, vivemos "em tempos de ideologia da eficiência e dos conhecimentos profissionalizados este problema costuma ser visto com simpática compaixão por sua suposta falta de atualidade" (MORAES, 2004, p. 141).

Moraes salienta a existência de múltiplos construtos ideológicos que tentam definir o que se "convencionou chamar de padrão civilizatório contemporâneo", evidenciando e integrando o conjunto do vocabulário cultural corrente, destacando dois construtos principais o da "sociedade da informação e o da sociedade do conhecimento." De tal forma que "a mídia, políticos, intelectuais de toda estirpe, seduzidos pelo irresistível avanço científicotecnológico dos dias atuais são unânimes ao prever a implacável tendência de alargamento dos limites da informação e do conhecimento" (MORAES, 2004, p. 142).

Fortalece-se a crença de que o capitalismo está cada vez mais robusto, e que por isso, ele é o telos inevitável de toda a sociabilidade humana, pois é o limite do processo civilizatório. Dá-se então a afirmação dos conceitos de sociedade da informação e de sociedade do conhecimento como "modelos" explicativos para a nova sociabilidade. Esses conceitos são muito próximos, porém interdependentes, cada um com suas especificidades.

Nesse sentido, o conceito de sociedade da informação, que se desenvolveu na década de 1990, "traduz a decisiva aposta na generalização do acesso aos modernos meios de informação e de transmissão do conhecimento, refere-se à forte cadência imposta pelas recentes e sucessivas gerações de tecnologias de informação e comunicação." Destaca-se o fato dessas "tecnologias asseguram a rápida e ágil transmissão de informação para todas as partes do planeta em tempo real e são definidas, em uníssono, como os elementos basilares da dinâmica da nova ordem e do exercício da cidadania" (MORAES, 2004, p. 142).

A ideologia da sociedade da informação propaga que as novas tecnologias são capazes de provocar efeitos altamente inovadores, que afetam a velocidade da distribuição de informações e também os processos cognitivos. Ao contrapor-se a isso, a autora, expõe as vísceras dessa ideologia, ao criticar seus arautos por acentuarem exageradamente a ideia de que a dinâmica da sociedade da informação ultrapassa inevitavelmente "os aparatos nacionais de educação e informação repercutindo sobre as formas de organização e operação do sistema escolar" (MORAES, 2004, p. 142).

Numa situação em que os arautos dessa ideologia chegam a propor que o sistema escolar deve abandonar o território próprio das normas e disciplinas e adaptar-se para o 
desempenho de papel no espaço da mercadoria, uma proposição extremamente complexa que "transcende desempenhos, papéis ou, até mesmo, os up-to-date desígnios de 'desterritorializar' o conhecimento humano." De tal forma que é necessário tratar com muito cuidado as questões envoltos às novas tecnologias, pois a ideologia da sociedade da informação apresenta-se de uma maneira extremamente sedutora, pois se apoia na ideia de que a universalização da "geração e distribuição da informação abririam a todos, democrática e equitativamente a possibilidade de dominar os chamados "códigos da modernidade." Esta construção ideológica apresenta-se como se o acesso à transmissão da inovação e do conhecimento representasse "a oportunidade para induzir uma cultura empreendedora e democrática, a criação de um clima favorável à inovação, elementos determinantes para um novo modelo de desenvolvimento baseado no aumento da produtividade" (MORAES, 2004, p. 143).

As formulações desenvolvidas pelos arautos da sociedade da informação, apesar de sedutoras revelam-se bastante problemáticas, pois, são incapazes de apreender a contradição do capitalismo global, a instabilidade de uma economia predominantemente financeira, especulativa e parasitária. Estas formulações desconsideram alguns fatores fundamentais como a diferença entre os países de capitalismo desenvolvido e os países de capitalismo periférico; o impacto da reestruturação produtiva no aumento do exército industrial de reservas, pois acentua o desemprego estrutural; a questão de propriedade dos meios tecnológicos e de informação, no que se refere a democracia. Por isso "tais formulações, no entanto, não levam em conta aspectos que lhes são determinantes. A rigor, seus rudimentos são pobres e pragmáticos." Já que omitem de forma escancarada, por exemplo, "que, cada vez mais, o poder econômico e a própria noção de desenvolvimento baseiam-se na posse e controle de informações e, portanto, bloqueiam as forças democráticas que reivindicam o direito de acessá-las, compreendê-las, ou dominar seus códigos" (MORAES, 2004, p. 144).

Com relação ao conceito de sociedade do conhecimento, essa autora salienta este é mais sutil que o de sociedade da informação, entretanto, acaba se confundindo e muitas vezes se sobrepondo a este. Porém, o conceito de sociedade do conhecimento acaba diferenciandose do de sociedade de informação ao vincular-se às questões concretas do mundo do trabalho.

É nesta perspectiva que Moraes (2004, p. 144) salienta que:

A 'sociedade' que se apresenta como 'do conhecimento' articula-se transformação do mundo laboral e à necessidade de novos conhecimentos que aparecem, aqui, como diferencial da competitividade -, ou, para não fugirmos às exigências do aggiornamento, novas 'competências', perpetuamente renováveis, instrumentos de capacitação do novo trabalhador (...) que deve ser flexível e adaptável às sempre novas circunstâncias do mundo do trabalho (...). Por estarmos no campo próprio das relações socioeconômicas, talvez fosse mais apropriado - e menos cínico - falar em 'economia do conhecimento' mais do que em 'sociedade do conhecimento'.

Esse ideário desenvolve seus pressupostos tendo como suporte ideológico o documento Educação: um tesouro a descobrir - relatório para a Unesco da Comissão Internacional sobre Educação para o século XXI, coordenado por Jacques Delors. Portanto, sustenta-se com base na pedagogia do "aprender a aprender", desenvolvendo um entendimento que despreza o fato de que os trabalhadores, em diferentes formas de organização da produção e gestão, sempre foram capazes de aprender.

Para se contrapor a esse ideário, apoiamo-nos no pensador italiano Antonio Gramsci desenvolveu, em Americanismo e Fordismo, uma interessante análise sobre essas questões na vida-daqueles-que-vivem-do-trabalho, ou simplesmente trabalham para viver, desde antes da invenção da imprensa na idade média. Gramsci descreve as destrezas e habilidades de Revista HISTEDBR On-line, Campinas, número especial, p. 154-174, ago.2010 - ISSN: 1676-2584 
profissões como linotipistas, estenógrafos, datilógrafos e compara com o trabalho do copista medieval, salientando que "a lentidão da arte de escrever medieval explica muitas [das] deficiências [do copista]: havia muito tempo para refletir, e portanto a 'mecanização' era mais difícil." De maneira tal - salienta Gramsci - que "o tipógrafo deve ser muito rápido, deve ter as mãos e os olhos em contínuo movimento, e isto torna mais fácil sua mecanização." Ao mesmo tempo, destaca que esses profissionais deve fazer um esforço imenso "para isolar o conteúdo intelectual do texto, muitas vezes apaixonante (e então trabalha-se menos e pior), a sua simbolização gráfica, e para se aplicarem só a esta , é talvez o maior esforço que se requer de um ofício. Todavia isso se faz e não mata espiritualmente nenhum homem" (GRAMSCI, 1978, p. 332).

De maneira tal, salienta Gramsci, que o cérebro do operário, no processo de adaptação não se mumifica, pelo contrário, atinge um estado de completa liberdade, pois só se mecaniza o gesto físico, ou seja, "a memória do ofício, reduzido a simples gestos repetidos, com ritmo intenso, alojou-se nos feixes musculares e nervosos, e deixou o cérebro livre e desimpedido para outras ocupações" (idem).

Gramsci revela de forma cabedal a capacidade dos trabalhadores, no contexto do fordismo-taylorismo, exercerem suas atividades produtivas, com gestos, movimentos e ritmos intensos e mecânicos, assim como ocorre naturalmente para se caminhar, mantendo o cérebro livre para outras ocupações, inclusive para pensar no que quiser.

Nesse sentido, Gramsci (1978, p. 332) afirma que:

Assim como se caminha, sem necessidade de refletir em todos os movimentos necessários para mover sincronicamente todas as partes do corpo, no modo determinado necessários para caminhar, assim acontece e continuará a acontecer na indústria para os gestos fundamentais do ofício; caminha-se automaticamente e ao mesmo tempo pensa-se em tudo aquilo que se quer.

Dessa forma, o pensador italiano, analisa e apreende a maneira como os empresários dos Estados Unidos no contexto do fordismo-taylorismo lidaram com o problema do controle, disciplina e adaptação dos trabalhadores, sabendo que o termo "macaco amansado" é apenas um recurso lingüístico, pois na realidade lidam com seres que pensam. Assim, "os industriais americanos compreenderam muitíssimo bem esta dialética inserida nos novos métodos industriais", afinal eles “compreenderam que 'gorila amansado' é uma frase, que o operário permanece 'infelizmente' homem e até que, durante o trabalho, pensa mais ainda ou que, pelo menos, tem muito maior possibilidade de pensar, pelo menos quando superou a crise de adaptação e não foi eliminado." De tal forma que, salienta nosso pensador, que o operário "não só pensa, mas não tira satisfações imediatas do trabalho, e compreender que o querem reduzir a um 'gorila amansado' pode levá-lo a um processo de pensamentos pouco conformistas" (GRAMSCI, 1978, p. 332).

\section{Para não concluir}

A realidade concreta do início do século XX revela uma crise histórica e estrutural de longa duração do capital. Esta crise do capital que se arrasta desde a década de 1970, conduziu o mundo para problemas que se agudizam em decorrência das ofensivas do capital. Este é o caso da crise ambiental/ecológico, das diversas formas de manifestação da violência, das pandemias etc. Mas, sobretudo, há o problema do desemprego e da precarização do trabalho.

De tal forma, que diante do mundo concreto a ideologia de uma educação funcionalista e cognitivista subordinada aos interesses do capital, fundada na pedagogia do 
aprender a aprender, da sociedade do conhecimento ou da sociedade da informação cuja premissa é desenvolver as capacidades cognitivas prescritas nos quatro pilares: "aprender a conhecer, aprender a fazer, aprender a viver juntos, aprender a ser", como se fossem as maiores novidades do século XXI. Nesse sentido, esta ideologia constitui-se num fetiche, um subterfúgio extremamente gelatinoso e tinhoso.

Nesse sentido, a assim chamada "Aprendizagem ao Longo da Vida", constitui-se em mais uma panacéia e também num paliativo ideológico, que possui um caráter utilitário, voltado para o interesse da valorização e acumulação do capital, da produtividade e da competividade, embora se apresente como um discurso altruísta recheado do assim chamado novo humanismo. Assim, também, devemos dar atenção especial à categoria de capital intelectual, pois se trata de uma ressignificação da categoria de capital humano no contexto do capitalismo de hegemonia financeira.

$\mathrm{Na}$ verdade, estamos vivendo uma época nebulosa e sombria para o trabalho, porém não a ponto de negarmos sua centralidade, pelo contrário, em decorrência da superexploração e precarização a que são submetidos milhões de homens, mulheres e crianças, sobretudo, na periferia do sistema do capital e nos países ditos emergentes. Afirma-se nessa época a eterna tendência do capital em sua insaciabilidade e incontrolabilidade na busca pela valorização.

Nesse sentido, é extremamente contraditório a ideia de estaríamos a experimentar a sociedade do conhecimento ou da informação, de que há uma tendência à concretização de uma "Aprendizagem ao Longo da Vida", de que estamos na sociedade do "aprender a aprender", que agora impera na vida dos indivíduos e da organização a primazia do "capital intelectual". Ou seja, a ideologia, ou se quisermos, a pedagogia do capital impõe a obrigatoriedade de cada indivíduo ser o principal responsável pela sua formação e inserção no mercado de trabalho, pela via da construção de competências para a empregabilidade.

Vivemos então a época da meritocracia individualista em que a ideologia da empregabilidade responsabiliza diretamente o indivíduo pelo seu êxito ou fracasso. Nesse sentido, ganha força também a ideia de empreendedorismo, onde o indivíduo é convidado a ser empresário de si mesmo.

\section{Referências:}

ALVES, Giovanni. A condição de proletariedade: a precariedade do trabalho no capitalismo global. Londrina: Práxis; Bauru: Canal 6, 2009.

ALVES, Giovanni. Dimensões da reestruturação produtiva: ensaios de sociologia do trabalho. Londrina: Práxis; Bauru: Canal 6, 2007.

ALVES, Giovanni; BATISTA, Roberto Leme; CAMMARANO GONZALEZ, Jorge Luis (Org.). Trabalho e educação: contradições do capitalismo global. Londrina: Práxis; Maringá: Massoni, 2006.

ANTUNES, Ricardo. Riqueza e miséria do trabalho no Brasil. São Paulo: Boitempo, 2006.

BATISTA, Roberto Leme, TUMOLO, Paulo Sérgio (Org.). Trabalho, economia e educação: perspectivas do capitalismo global. Londrina: Práxis; Maringá: Massoni, 2006.

BATISTA, Roberto Leme; ARAUJO, Renan (Org.) Desafios do trabalho: capital e luta de classes no século XXI. Londrina: Práxis; Maringá: Massoni, 2003 
CANÁRIO, Rui. “A aprendizagem ao longo da vida”: análise crítica de um conceito e de uma política. In: CANÁRIO, Rui (Org.). Formação e situações de trabalho. Porto: Porto Editora, 2003.

DUARTE, Newton. Vigotski e o "aprender a aprender": crítica às apropriações neoliberais e pós-modernas da teoria vigotskiana. 2. ed. Campinas: Autores associados, 2001.

FIGARI, Claudia; ALVES, Giovanni (Org.). La precarización del trabajo em América Latina: perspectivas del capitalismo global. Londrina, Práxis, Bauru, Canal 6, 2009. FONSECA, Vitor da. Aprender a aprender: a educabilidade cognitiva. Porto Alegre: Artmed, 1998.

GRAMSCI, Antonio. Americanismo e fordismo. In: Obras escolhidas. São Paulo: Martins Fontes, 1978.

MORAES, Maria Célia Marcondes de. Incertezas nas práticas de formação e no conhecimento docente. In: MOREIRA, Antonio Flavio Barbosa; PACHECO, José Augusto; GARCIA, Regina Leite (Org.). Currículo: pensar, sentir e diferir. Rio de Janeiro: DP\&A, 2004.

NONAKA, Ikujiro; TAKEUCHI, Hirotaka. Criação de conhecimento na empresa: como as empresas japonesas geram a dinâmica da inovação. Rio de Janeiro: Campus, 1997.

PAPADOPOULOS, George S. Aprender para o século XXI. In DELORS, Jacques (Org.). A educação para o século XXI: questões e perspectives. Porto Alegre: Artmed, 2005.

SOTELO, ADRIÁN. La reestruturación del mundo del trabajo: superexplotación y nuevos paradigmas de la organización del trabajo. México, D.F. Universidad Obrera de México; Editorial Itaca; Morelia, Mich: Enat, 2003.

STEART, Thomas A. Capital intelectual: a nova vantagem competitiva das empresas. Rio de Janeiro: Campus, 1998.

STEWART, Thomas A. A riqueza do conhecimento: o capital e a organização do século XXI. Rio de Janeiro: Campus, 2002.

\footnotetext{
${ }^{1}$ Doutor em Ciências Sociais, professor livre docente do Departamento de Antropologia e Sociologia da UNESP campus de Marília, coordenador da Rede de Estudos do Trabalho - RET.

${ }^{2}$ Doutorando em Ciências Sociais, professor assistente da Faculdade Estadual de Educação de Paranavaí-PR, membro da Rede de Estudos do Trabalho - RET.

${ }^{3}$ Alves, 2007 e 2009; Antunes, 2000 e 2006; Figari e Alves, 2009; Sotelo, 2003.

${ }^{4}$ Esta discussão de Canário é interessante, pois, as concepções, os conceitos e categorias forjadas na Europa, acompanham a evolução da UNESCO e rebatem diretamente em países da antiga periferia capitalista como é o caso do Brasil.

Recebido 10/06/2010

Avaliado 14/06/2010
} 